\title{
APROXIMACIÓN A LOS FUNDAMENTOS CONTABLES, LEGALES Y MORALES DEL MÉTODO DE CARGO Y DESCARGO O DATA POR EL QUE SE RENDIAN CUENTAS
}

\author{
AN APPROACH TO ACCOUNTING, LEGAL AND MORAL \\ FOUNDATIONS OF THE CHARGE AND DISCHARGE SYSTEM, \\ A METHOD USED FOR ACCOUNTABILITY
}

\author{
Susana Villaluenga de Gracia
}

\begin{abstract}
RESUMEN
El cargo y descargo o data tradicionalmente se ha considerado como una de las formas empleadas para tomar la cuenta y razón a un sujeto que administraba bienes o gestionaba rentas en nombre de un tercero. Consistía en poner a este sujeto como cargo en contra lo que se le entregaba; haciéndole descargo de lo que el mismo demostraba haber pagado o empleado. La diferencia entre el cargo y el descargo constituía el alcance, en contra o a favor del administrador o gestor. Esto permitía determinar la posición deudora o acreedora del sujeto titular de la cuenta con el dueño del negocio por el que actuaba.
\end{abstract}

Tradicionalmente, este procedimiento ha sido estudiado desde el punto de vista contable, como prueban la gran cantidad de trabajos elaborados al respecto. La mayoría han venido analizando el papel del cargo y descargo o data en la contabilidad de diferentes organizaciones públicas y privadas a lo largo del tiempo. Sin embargo, en la forma de planificar la cuenta por cargo y descargo hemos observado aspectos que van más allá de lo puramente contable. En concreto, adivinamos una forma de proyectar la cuenta y razón en tres dimensiones: contable, jurídica y con un matiz religioso o moral, a cuyos fundamentos nos referiremos en este trabajo.

\begin{abstract}
The charge and discharge accounting system has traditionally been considered as one of the forms used to make the account and reason to a steward who would be responsible of managing the property of another person. This procedure consisted in charging the steward with the sums for which he was responsible, everything that was received to administer or to manage; the steward would then be discharged of all legitimate payments that he would have demonstrated to have paid at the end of his management. The difference between the charge and the discharge was the scope, for or against the administrator or manager. This procedure determined the position of debit or credit of the person whom the steward was managing the property for.

Conventionally, this procedure has been studied from an accounting point of view, as evidenced by the many written works that have been published to that regard. Most have been analyzing the role of the charge and discharge in different public and private organizations over time. Nevertheless, in the charge and discharge accounting we have observed aspects that go beyond the purely countable one. More
\end{abstract}

DE COMPUTIS Revista Española de Historia de la Contabilidad Spanish Journal of Accounting History 

morales del método de cargo y descargo o data por el que se rendían cuentas

specifically, we can guess a way of projecting the account and reason in three dimensions: countable, legal and with a religious or moral connotation, to whose foundations we will refer to in this work.

PALABRAS CLAVE:

Rendición de cuentas, cargo y descargo o data.

KEYWORDS:

Charge and discharge, track and reason, accountability, control.

\section{Introducción}

Para comenzar a hablar del cargo y descargo o data conviene, en primer lugar, centrarse en su significado contable más general. Así, este procedimiento consistía en poner en contra o en cargo y obligación al administrador o gestor del bien o derecho recibido en gestión de cobro; y luego descargo y razón de lo que demostraba haber pagado o empleado de acuerdo a la ley, a la norma interna o al libramiento del órgano ejecutivo o titular de esos bienes o derechos. La diferencia constituía el alcance normalmente en contra del sujeto al que se le tomaba cuenta, por ser lo recibido superior a lo empleado. En ese caso el dador de la cuenta estaba forzado a hacer finiquito y depósito del bien o importe por el que era alcanzado porque "es obligado al administrador de entregar al señor los bienes que del rescibio que no están justamente gastados y poner lo en possession dellos” (Castillo, $1542^{1}$ : $8 \mathrm{r}$ ).

Si nos atenemos al significado más general del cargo y descargo, podemos decir que hacer o dar cargo es tanto como recibir el sujeto responsabilidad, como recibía al que se le encomendaba un oficio encargo del mismo, según señala Covarrubias en su Tesoro de la Lengua Castellana (1611): “y por alusión los oficios, y gouiernos se llaman cargos por la carga y cuidado que traen en consigo, y en la lengua latina se juega del vocablo al sonido. Honos \& onus”. Por el contrario, se tenía como descargo el hecho de "descargar la conciencia, restituir lo mal llevado" o "desembarazo de los que cargan la conciencia”. Es decir, en el descargo se daba satisfacción, respuesta o excusa del cargo hecho. En definitiva, la clave del cargo y descargo o data está en la carga u obligación aneja a un estado, empleo u oficio y en esto estaba la mayor responsabilidad y, por tanto, la obligación de rendir cuentas al final.

El uso del cargo y data estaba presente en las cuentas de las administraciones reales, señoriales, municipales y judiciarias (González Ferrando, 1988: 191) y se mantuvo en el tiempo porque se ajustaba a la necesidad de controlar la actuación de cualquiera encargado del manejo de rentas, tal y como ocurría con los funcionarios o cualquiera involucrado en la recepción, entrega y custodia de bienes o dineros públicos (Hernández Esteve, 2007: 163). Por tanto, tiene una fundamentación de base que el procedimiento de cargo y data surja vinculado a la rendición de cuentas del que tiene un

${ }^{1}$ Conviene aclarar que a esta de Burgos le siguieron otras dos ediciones en Salamanca: una de 1542 y otra de 1551 (Hernández Esteve, 2007: 188).

DE COMPUTIS Revista Española de Historia de la Contabilidad Spanish Journal of Accounting History

No. 19

Diciembre 2013 
encargo o responsabilidad frente a una colectividad, poniéndose de manifiesto de forma clara su matiz contable.

Partiendo de su principal significado, el contable, el cargo y data era una de las formas de llevar la cuenta y razón, según advierte Diego del Castillo en su Tratado de Cuentas (1522): a) data y recibo; b) debe y debe haber; y c) cargo y data (1542: 3v). En esto conviene advertir que la cuenta y razón consiste en "hacer patente la forma en que se ha manejado alguna dependencia o negocio, para que la parte interessada quede satisfecha del proceder de quien lo executo”. Así, hacer algo con cuenta y razón vendría a expresar "el modo de hacer alguna cosa con atención y proporción, sin falta ni superfluidad” (RAE, 1729).

En esta formulación de la cuenta y razón por cargo y descargo se pueden apreciar ciertas cuestiones bajo diferentes puntos de vista. Primero desde un punto de vista contable, está la forma de poner de manifiesto el resultado de la gestión de unas rentas por diferencia entre el importe del cargo y descargo del que resultaría el alcance, que sería la obligación o bien el derecho del gestor con el titular de las mismas (saldo de la cuenta). En segundo lugar, estaríamos ante la obligación legal que tiene el sujeto contable de entregar o restituir lo mal llevado. Y en tercer lugar, con una visión más transcendental, pensaríamos en la obligación que tendría un sujeto de descargar su conciencia librándose del encargo que se le encomendó. Por tanto, considerando estos puntos de vista, adivinamos una forma de planificar la cuenta y razón en tres dimensiones: contable, jurídica y moral, a cuyos fundamentos pretendemos aproximarnos a continuación.

\section{Fundamentos contables del cargo y data}

Según puso de manifiesto Esteban Hernández Esteve, mientras que sobre la partida doble se conocen varios tratados, los aspectos relativos al cargo y data proceden de las conclusiones extraídas del estudio de las numerosas muestras conservadas en los archivos y las simples alusiones que a este sistema se hacen en los documentos contables, pues no se ha encontrado un manual específico sobre el cargo y data y los que se conocen son textos insertos en libros de objetivos más amplios (2007: 223). La mayoría de éstos, como veremos, de naturaleza jurídica.

\section{1.- El cargo y data en los tratados contables}

Hasta la aparición de El Libro de Caxa y su Manual de Bartolomé Salvador de Solórzano (1590), los tratados existentes en España refieren los aspectos contables y jurídicos de las cuentas, donde contabilidad y derecho forman parte de un sistema ligado tradicionalmente a la asunción de responsabilidades. De hecho, por ejemplo, algunos autores ven el Tratado de Cuentas $(1522)^{2}$ del jurisconsulto Diego del Castillo,

${ }^{2}$ Conviene aclarar que a esta de Burgos le siguieron otras dos ediciones en Salamanca: una de 1542 y otra de 1551 (Hernández Esteve, 2007: 188).

DE COMPUTIS Revista Española de Historia de la Contabilidad Spanish Journal of Accounting History 
ampliamente estudiado por los historiadores de la contabilidad, un tratado más jurídico que contable (Vlaemminck, 1961: 164, Donoso, 1996: 125; y Caunedo, 2003: 146). Igualmente, aproximándose a su naturaleza jurídica, Francisco Aced y Bartrina (1941: 32) calificaba la contabilidad por cargo y data como "contabilidad administrativa, oficial o pública y judiciaria o forense”.

En el tratado de Solórzano los conceptos de cargo y data aparecen equiparados a los de debe y haber de la partida doble. De hecho, el autor lo deja bien claro al hablar del uso del "ha de auer" (1590, cap. XI: 16v): "Ha de auer fulano tantos marauedis que dio de contado por tal razon, es lo mismo que decir, descarguen se le a fulano tantos maraudis, que dio de contado por tal razon,...” No ocurre lo mismo al tratar el concepto de cargo (1590, cap. XI: 16r): “...y acabado de escriuir el nombre de la tal persona se diga luego, Deue en tantos de tal mes tantos marauedis que le di de contado por tal razon, y no diga cargo;...” En razón de esto último dice que es "porque este nombre de cargo, es para escriuirle en las partes y lugares donde se acostumbra, como es en libros de pliego oradado, y en cuentas que se toman por autoridad de justicia,...” En esto último, por tanto, vislumbramos nuevamente el matiz jurídico del cargo y data.

Otro tratadista, Jócano y Madaria en su Disertación crítica y apologética del arte de llevar cuenta y razón (1793), presenta el cargo y data referido a los nombres de las dos divisiones de una cuenta que contienen la “acción” y la "pasión” del sujeto titular (Disertación, punto primero: 5): "Si se llaman cargo la una, y data la otra, explicarán que el cargo contiene las Partidas, que son en contra del título de la Cuenta, y la data las que son á su favor.” El autor llega más lejos aún relacionando los dos significados (Disertación, punto primero: 5-6): "Por lo que á mí toca, llámense cargo y descargo, debe y haber, débito y crédito, recibo y gasto, ó como cada uno quisiere. [...] con tal que se distingan y separen á un lado las Partidas en pro, y á otro las en contra:”.

La misma confusión se manifiesta en tratados y manuales contables por partida doble relativamente recientes como en el de Bernardino Donate y Alberola (1885: 25), donde se refiere a la duplicidad de las operaciones "manifestándose por un registro de cargo ó débito y otro de abono ó data”. Incluso, usa tales conceptos para dar sentido al método: “y de esta proposición fundamental proviene la denominación de partida doble ó dobles partidas, puesto que en toda operación hay siempre dos partidas: la del cargo y la de la data.” Es evidente que en este caso el concepto de cargo y data pierde su matiz jurídico de los primeros tratados para adoptar el puramente contable de cargar o abonar, que resulta de anotar en el debe y haber de una cuenta, respectivamente.

Poco más se puede saber de la evolución del cargo y data en los demás tratados contables que lo recogido ya por estos autores, tal y como señala Hernández Esteve. Sin embargo, cabe referirse ahora a la naturaleza del cargo y data a partir de las conclusiones extraídas del estudio de las numerosas muestras conservadas en los archivos.

\section{2.- El cargo y data a la luz de la documentación contable estudiada}

Si nos centramos en España, como sostuvimos más arriba, el uso del cargo y data estaba ligado fundamentalmente a la contabilidad de la Administración Pública, las

DE COMPUTIS
Revista Española de Historia de la Contabilidad Spanish Journal of Accounting History 
corporaciones religiosas y las entidades sin fines lucrativos. Referidos al primer caso podemos mencionar las investigaciones sobre los contadores municipales en la Corona de Castilla durante los siglos XIV-XVIII (García Ruipérez, 2005), donde se pone de manifiesto el uso generalizado de este procedimiento para tomar las cuentas. También en el Ayuntamiento de Sevilla hasta mediados del siglo XVI la rendición de cuentas del mayordomo se hacía por cargo y data (Rubín, 2010: 4). En la Real Hacienda de Indias en la etapa anterior a 1528 se llevaba un sistema de libros particulares por oficios, mediante el método de cargo y data (Donoso, 2008: 64). Incluso, cuando en las cuentas centrales de la Real Hacienda castellana se utilizó el "Libro de Caxa" entre 1592 y 1621, coexistiendo con el de cargo y data (Hernández Esteve, 1985 y 1986), para las Indias no se pasó del cargo y data (González Ferrando, 1994). Igualmente se utilizó el cargo y data en las cuentas públicas de ultramar hasta que la instrucción de 25 de junio de 1850 obligó a utilizar la partida doble (Mirón, Escobar y Hernández, 2011: 124).

Asimismo, según afirma González Ferrando, la contabilidad señorial hasta bastante tiempo después de la publicación del tratado de Solórzano se llevaba por el procedimiento de cargo y descargo o cargo y data (1991: 714). Esto lo confirma Jesús Damián López-Manjón que, fruto de la revisión bibliográfica y del estudio de las fuentes primarias existentes al respecto, concluye que el cargo y data era un método contable utilizado en las casas nobiliarias españolas en el siglo XIX para averiguar el balance de sus administradores, pues la partida doble no era un instrumento para la gestión de los patrimonios nobiliarios (2009: 45).

Del mismo modo el cargo y data era un procedimiento utilizado en la contabilidad de entidades sin fines lucrativos, como ha quedado demostrado para el Hospital de Santa Marta de Sevilla (siglos XV a XVI) (Hernández Borreguero, 2008), el Hospital de San Julián de Albacete entre 1838 y 1859 (López y Pérez, 2007) y el Hospital de la Caridad de La Coruña en el siglo XVIII (Salvador y Ruiz, 2011). A éstos hay que añadir la contabilidad de colegios y universidades, como el Colegio-Universidad de Osuna en la segunda mitad del siglo XVIII (Damían y Gutiérrez, 2006)

Con todos los trabajos mencionados, donde mayor presencia ha tenido el cargo y data, además de en la contabilidad de la Administración Pública, ha sido en la contabilidad de las entidades religiosas, como ha quedado demostrado para la parroquia de la Villa de Agüimes (1730-1830) (Calvo y Castro, 2005), la Santa Capilla de San Andrés en Jaén (1650-1900) (Lillo y Álvarez, 2006), el Monasterio de Silos en la Edad Moderna (Maté, Prieto y Tua, 2008), el Monasterio de Oseira (1614-1698) (Gallego, Rivero y Ramos, 2007), la Fábrica de la Catedral de Segovia en el siglo XVI (Cillanueva, 2008 y 2010) o la Catedral de León (1880-1901) (Rodríguez, Morala, Gutiérrez y Fernández, 2010), entre otros.

Con todo lo anterior, la opinión unánime es que el cargo y data era un sistema orientado a la rendición de cuentas a terceros, que jugó un papel decisivo en el control, razón por la cual se mantuvo en el tiempo (Hernández Esteve, 2007: 163). De hecho, Casares (2009: 8) hablando de la ejecución de las obras de la Alhambra en el siglo XVI, señala que el cargo y data jugó un papel decisorio en el control, pues los agentes de la

DE COMPUTIS Revista Española de Historia de la Contabilidad Spanish Journal of Accounting History 
Corona debían dar cuenta por este procedimiento de las entradas y salidas del arca con todo detalle, según las instrucciones contables de 1551. Asimismo, para una época más tardía, Carmona, Céspedes y Donato (1997: 470-472), al estudiar la contabilidad de las Salinas de Roquetas (1800-1803), advierten que aún con la reforma de la organización burocrática más compleja el método servía al negocio para evitar fraudes y malversaciones.

También la mayoría de los autores coinciden en señalar que pese a ser un método anticuado en muchos casos, el cargo y data resultaba suficiente y suministraba los datos necesarios y precisos, tanto en la vertiente informativa como para la posible toma de decisiones. Otros autores, además de estas generalidades, hacen hincapié en nuevas excelencias del cargo y data, señalando que era fácil de usar y no requería de una formación especializada (Carmona Pidal, 2001: 251 y 252); permitía determinar la renta generada, señalando los ingresos y gastos y, en otros casos, las entradas y retiradas de efectivo (Capelo, 2007: 473); y facilitaba el control de los ingresos y los pagos realizados, la persona que los percibía, si era por la cantidad correcta y cómo se empleaban (Calvo, 2005: 178).

\section{Fundamentos jurídicos}

Si bien, como hemos manifestado más arriba, el cargo y data ocupa un lugar destacado en la literatura contable; es posible que sus fundamentos adquieran mayor significación en el contexto jurídico, ligado al derecho de obligaciones. En virtud a esta conceptualización, el cargo actuaba en contra de enjuiciado y el descargo a favor. De la misma forma, abundando en estos aspectos, por derivación también hablamos de testigo de cargo, el que declara en contra del procesado; y testigo de descargo el que declara a favor. En función de cuyos testimonios juzga el juez la causa. Así, en los términos de cargo y data media cosa juzgada, vinculada a la cuenta que rinde ante la autoridad el justiciado cumpliendo con la Ley natural haciendo descargo de su honra con todos los papeles y pruebas que tenía; y por extensión en la Ley divina ante Dios (Pérez, 1624: 102): "Y que por el fuero Diuino instituydo, y guardado por Dios en el primer delicto del primer hombre, no puede ninguno ser juzgado, ny condenado sin cargo, y descargo.”

En este sentido, el punto de partida para estudiar los aspectos jurídicos del cargo y data puede estar en el artículo que Pierre Jouanique publicó en 1987 sobre la regla: "Quien recibe, debe". El autor identifica el cargo y data con la cuenta que estaban obligados a rendir los factores a su principal, cuya naturaleza jurídica analiza apoyándose en la lectura del Digesto romano $(533)^{3}$. En esta obra el cargo y data se

3 En este caso se advierte como esta cuenta debe estar encabezada por el inventario, "a fin de que puedan distinguirse con separación las partidas de cargo y data”, procurando poner en ellas el origen las mismas para conocer su legitimidad. Luego el alcance se pone de manifiesto en la obligación que tiene el tutor en entregar al pupilo lo que resultase: “y entreguen lo que resulta á su favor” (Digesto, Título III, p. 31): "para manifestar que el tutor está obligado á entregar al pupilo todo lo que sea de este y hubiere quedado en su poder después de haber rendido cuentas, y que además deberá indemnizarle de todos los perjuicios

DE COMPUTIS Revista Española de Historia de la Contabilidad Spanish Journal of Accounting History 
relaciona con la cuenta que el tutor debe dar al pupilo de los bienes administrados por él. En esto se entiende que la diferencia a devolver al pupilo es el resultante entre lo recibido y lo empleado. Igual proceder se sigue para el mismo caso después en Las Siete Partidas donde se obliga al tutor a rendir cuentas a su pupilo de la administración de la Hacienda por cargo y data ${ }^{4}$.

Por tanto, centrado en la relación de dependencia entre el que rinde la cuenta y el que la recibe, la rendición de cuentas por cargo y data se ajustaba a un proceso en el que Jouanique (1987: 248 y 252) diferencia cuatro fases:
a) Examen de justificantes
b) Verificación de las cifras
c) Pago del saldo en efectivo
d) Liquidación de la cuenta

Mientras que el cargo donde se encontraban los derechos de cobro y los bienes recibidos no necesitaba justificación; la primera fase en la que tiene razón la data, elaborada con los pagos, debía ser justificada por el dador de la cuenta. Precisamente en relación a la elaboración de la misma, en un libro de instrucción de escribanos se dice que la data debe quedar totalmente justificada (Febrero, 1797, Libro $3^{\circ}$, Tomo $1^{\circ}$ : 432):

“... se ha de pretender para abreviar, que las reconozca éste, y presente los documentos calificativos de la data, y en virtud del reconocimiento, ya los produzca, ò no en el término que se le prefina, que el Escribano liquide con citación suya ante todas cosas las partidas no justificadas, y que con la propia citación y audiencia se apruebe la liquidación, y pase en autoridad de cosa juzgada, aprobada debe pedir que por lo que no resulte documentado, se expida mandamiento de execucion contra él como alcance líquido, ya en la cuenta saque, ò no alguno contra sí.”

Tanto el cargo como la data o descargo, una vez confeccionados, debían ir convenientemente firmados por los contadores, que aquí actuaban de jueces-auditores, y las partes con la fe de un escribano. Pese a elaborarse el cargo con antelación a la data se solían firmar a la vez, es decir, al tiempo de terminar la data. De esta manera se evitaba que si los contadores no recibiesen como buenas algunas partidas de la data, el dador de la cuenta quedase obligado a asumir el cargo. Así queda explícito en un Libro de práctica de la administración, y cobranza de las rentas reales (De la Ripia, 1796, Tomo III, p. 5):

que le causó con dolo ó culpa; ó porque hizo lo que no debió hacer; ó al contrario. Aunque por lo regular, á la obligación de dar cuenta, vá unida la de volver lo que restare á favor del pupilo.”

${ }^{4}$ En concreto, en la Partida tercera, Título 18, Ley 94, se hace mención a la cuenta que debían rendir los "et que quando fuere acabado el tiempo en que lo habien á tener en guarda quel darán cuenta et recabdo bien et lealmente de todas las cosas del huérfano que tovieron en guarda et pasaron á su poder” (p. 612).

DE COMPUTIS

No. 19
Revista Española de Historia de la Contabilidad Spanish Journal of Accounting History 
“..., no queriendo firmar el cargo hasta el fin de la data, temiendo que no se les haya de recibir en data algunas partidas, y quedan sujetos á ser executados enteramente por el cargo, mayormente quando no han recibido algunas partidas, y por el cargo parece se supone que sí; porque lo cierto es, que la confesión del cargo no se puede executar, sin que se acepte el descargo y data en lo que se debiere, y fuere justo, porque es un acto individuo y connexo que no se puede separar ni partir, mas á cautela se suele decir firman ó consienten el cargo con calidad que se les ha de baxar tales cantidades entrada por salida, o recibiéndoles tales descargos y excepciones.”

Es en la tercera y en la cuarta fases mencionadas (redacción del escrito de finiquito con fecha, sumas y saldo final) donde se centra la sustancia de este proceder que recuerda al derecho de obligaciones. Es decir, el presentador de la cuenta es deudor del saldo, que es la deuda que resulta de su gestión, porque el saldo es el excedente de los cobros sobre los pagos; y, por tanto, quien recibe, debe (Jouanique, 1987: 250).

Una vez aprobada la cuenta, tomándose como cosa juzgada y por lo que no resultase documentado se expediría mandamiento de ejecución en contra del presentador de la cuenta como alcance líquido. Así lo reconoce Febrero: "Si las cuentas se aprueban, y reconocen en juicio con la solemnidad legal, y el que resulta alcanzado, consiente el alcance, traen aparejadas execucion; pero si falta este requisito, no son exequibles”. La razón de la ejecución del alcance era porque "cargo es confesión de lo recibido con obligación de responder de ello, y cierto indubitado y efectivo como corroborado con juramento, que es segunda confesión” (Febrero, 1797, Libro 3․ Tomo $1^{\text {o: }}$ :431-433). Asimismo, “y à la data ò partidas que debiendo estar documentadas, no lo están, no se debe dar crédito, à causa de faltarles la justificación que las debe acompañar, y asi queda líquido en su importe el encargo, por ser lo mismo que sino las datára” (Febrero, 1797, Libro $3^{\circ}$, Tomo $1^{0}$ : 432).

En otro orden de cosas, en caso de que el que debiese rendir cuentas no hubiese justificado como debe la data, el alcance se ejecutaría en contra por lo que importase la data injustificada "porque esto se presume figurado, voluntario, y puesto con el único objeto de cubrir el cargo, por lo que no merece aprecio” (Febrero, 1797, Libro 3․ Tomo $\left.1^{\mathrm{o}}: 432\right)$.

El cargo y data permaneció vinculado a la rendición de cuentas de los receptores de rentas reales, tal y como se recoge en la Recopilacion de las leyes destos Reynos, hecha por mandado de la Magestad católica del Rey don Philippe Segundo nuestro Señor. En el caso de los receptores de penas de cámara se dice concretamente (Libro II, Título XIIII, Ley XII): “Otrosi, que no pague ninguna cosa de las dichas penas, sin que primeramente la dicha persona tome la razon de las cedulas y mandamientos que para ello se diere, porque pueda tener buena cuenta de su cargo y data:” En el Libro octavo, Título XXVI, Ley XXII se señala, de forma más explícita, que el receptor "ha de ser obligado à dar a los dichos Contadores de penas de Camara en fin de cada un año una relación jurada y firmada de su cargo, y data”.

DE COMPUTIS Revista Española de Historia de la Contabilidad Spanish Journal of Accounting History 
En la Novísima Recopilación de las Leyes de España se reconocía la tasación de los días que los escribanos se hubiesen empleado en hacer las sumarias y probanzas de la semana formando "carta cuenta segun estilo y práctica de los Tribunales de España" (Libro V, Título X, Ley V, Duda 3).

Paradójicamente a lo que cabría esperar, en los siglos posteriores el cargo y data permanece en los textos jurídicos, pese al avance de la partida doble en los textos contables. Así, el cargo y descargo o data se reconoce como el procedimiento habitual por el que los contadores tomaban cuenta a los receptores y administradores de la hacienda de un tercero. En un libro de Marcelo Martínez Alcubilla (1848: 309-310) se indica en relación con los Procuradores que, además de guardar con todo orden los documentos, escrituras, instrucciones y otros papeles, "Deben llevar un libro de cargo y data en que pongan con toda distinción y claridad las cantidades que reciben y las que pagan”. Finalizado el negocio debían dar cuenta a su principal.

Joaquín Abella (1885: 372), refiriéndose al contrato con el depositario de los fondos municipales, el antiguo mayordomo de propios y caudales nombrado por el Ayuntamiento o Concejo, decía que tenía "obligación de dar cuenta exacta y puntual de todas las partidas de entrada y salida con cargo y data de su distribución y pago”.

Además, el cargo y data se aplicaba como mecanismo de intervención de las finanzas en las colonias. En el Diccionario de la Administración de Filipinas un Decreto del Gobierno General de 29 de octubre de 1875 (1887: 253-255) determinó que con el fin de organizar hasta donde sea posible la intervención de ramos locales en las subdelegaciones provinciales y hasta el momento en que se dictasen las medidas oportunas, entre los deberes de los interventores estarían: "Examinar con prolijidad el número y clase de documentos de cargo y data que sirvan de justificantes para la formación del acta de arqueo y desechar los que no estuviesen entendidos con arreglo á las instrucciones en vigor".

En el Estatuto Municipal de 8 de marzo de 1924 (Art. 584) se sigue recogiendo la figura de los depositarios señalando que "deberán rendir cuentas trimestrales de caudales debidamente justificadas, acompañando relaciones por capítulos de cargo y data, y de los mandamientos de ingresos y pagos respectivos. Al finalizar los ejercicios formularán cuentas anuales de las operaciones ajenas al presupuesto ordinario municipal justificándolas en la misma forma”.

\section{Implicaciones morales}

Los términos de cargo y descargo refuerzan su significado si consideramos su matiz religioso al relacionarlos con la forma en que el cristiano está obligado a rendir cuenta a Dios de los bienes recibidos. En este caso la rendición de cuentas se plantea como un juicio individual en el que el juez es Dios, que pagará a cada uno de acuerdo al uso de sus méritos, sentenciando positiva o negativamente según la actitud de servicio que haya tenido para la misión que se le encomendó.

DE COMPUTIS Revista Española de Historia de la Contabilidad Spanish Journal of Accounting History 
A estas cuestiones se refiere la parábola de los talentos (Mt 25, 14-30 y Lc 19,1227), donde se intenta hacer reflexionar sobre el uso que cada cristiano hace de los dones y gracias que Dios concede. La misión del beneficiario de los dones es hacerlos fructificar. En definitiva, el fin de esta parábola es infundir la responsabilidad e inculcar al cristiano una forma de vida antes del juicio final o la rendición de cuentas ante Dios.

\section{1.- La confesión y el testamento en descargo de la conciencia}

En virtud a las pautas de vida señaladas por la religión católica, lo que debe pretender el individuo es atender con responsabilidad su encargo durante el tiempo que habite en el cuerpo para que a la hora del juicio la cuenta salga justa.

El ajuste de la cuenta comienza poniendo en orden el cargo, que está en la conciencia de cada cristiano, entendiéndose ésta como la ciencia de uno mismo o ciencia ciertísima, y casi certinidad de aquello que está en nuestro ánimo, bueno o malo (Covarrubias, 1611). Luego, a través del sacramento de la penitencia o el testamento se actuaba para descargo de la conciencia. Ambos instrumentos son claves para preparar en la tierra el momento de llegar a Dios y conseguir el gozo de la felicidad eterna.

Para la confesión el cristiano se imagina rindiendo cuentas ante Dios de sus actos, dejando actuar su propia conciencia y haciendo examen de ella. El examen de conciencia se convierte así en una contabilidad moral, que requiere una valoración de las actuaciones de la vida en la tierra, haciendo uso del método de cargo y descargo: “y mira que de ajustar tú bien la cuenta ahora, penderá acaso no menos que tu condenación ó salvación: pues ha de ser este librete por donde la dés después á tu Señor el dia del juicio: y asi mira cómo la ajustas ahora bien con despacio, ya que Dios te concede este tiempo para ello” (Fray Juan de Zamora, 1799: 369).

El ajustar la cuenta motivaba en el cristiano cierta angustia, que se hace patente en los escritos de algunos autores. En el antes citado, El eclesiástico perfecto, de Fray Juan de Zamora (1799: 370), el autor se lamenta:

“¡Mas, oh! que aun sin tomar la pluma para formar el cargo y data de esta cuenta, estoy ya lleno de pavor, temiendo con fundamento mi condenacion; porque, á excepción de unas limosnas cortas que he expendido entre los pobres que llegaban á mi puerta, acaso por vanidad, ó porque no me notasen de avariento, ó por la importunación con que me las pedían muchas veces, no veo qué partida pueda dar para descargo de lo mucho que monta el cargo de lo recibido. ¡Ay de mí! ¡y ay de quien habiendo gastado sin cuenta, como yo, la renta de la Iglesia, se viere precisado á darla en el justo tribunal de Jesuchristo, sin haberla primero evacuado en el tiempo de misericordia con verdadera penitencia!

Haciendo recopilatorio del cargo y descargo, el cristiano se anticipa al juicio tomando conciencia de su verdadera responsabilidad en la tierra al objeto de lograr un

DE COMPUTIS Revista Española de Historia de la Contabilidad Spanish Journal of Accounting History 
comportamiento adecuado que concluya en una sentencia favorable en el cielo (Fray Juan de Zamora 1799: 372):

"Ea pues, Señor, scio quid faciam. Ya veo á vuestra luz lo que debo, y me conviene hacer. Echaré de mi casa quanto sea supérfluo: ceñiré mi gasto en comida, vestido, y todo lo demás, á solo lo preciso, y tan preciso, que no me quede duda de ser verdaderamente necesario; y todo lo demás que tengo, ú honestamente adquiriere en adelante, lo daré á los pobres en limosna: pues sé que quanto pusiese ahora en sus manos lo deposito en las vuestras para entonces, que lo aceparéis en vuestro juicio por satisfacción, no solo de este cargo, sino de quantos otros me haga mi enemigo en él. Así Dios mio, lo resuelvo firmemente con el favor de vuestra gracia: y así tendré ganados amigos, que quando salga de esta vida, me reciban en las moradas eternas de la Gloria.”

Sin embargo, es muchas veces solo al borde de la muerte cuando el individuo repara en la caducidad y el irremediable fin de su vida e intenta prepararse para el juicio y la vida espiritual eterna procurando ajustar en lo espiritual y temporal su cuenta. Esta doble declaración que se manifiesta en la propia entidad del ser, donde conviven irremediablemente ambos aspectos, ha sido representada en diferentes ocasiones en nuestra literatura y en el arte con la presencia del cura y del escribano en el lecho del moribundo. Sin ir más lejos, en el Ingenioso hidalgo Don Quijote de La Mancha es el propio protagonista al borde de la muerte el que requiere a ambos (II, c.74):

"Yo, señores, siento que me voy muriendo a toda priesa; déjense burlas aparte, y tráiganme un confesor que me confiese y un escribano que haga mi testamento; que en tales trances como éste no se ha de burlar el hombre con el alma; y así, suplico que en tanto que el señor cura me confiesa, vayan por el escribano”.

En los manuales de moral donde se trataban diversas prácticas sobre la confesión, al abordar la de los enfermos se recomendaba averiguar primero si el que confesaba estaba en peligro de muerte. En ese caso, el cura debía asegurarse de que hubiese recibido el sacramento y la extremaunción y llamar al escribano para hacer el testamento, diciéndole algunas palabras para moverle a contrición y dolor de sus pecados, confesarle en lo más grave y darle la absolución. Mas si hubiese tiempo para ello, se iría examinando más largamente la conciencia: "Pregunte después si tiene algún cargo de conciencia de restitiucion de honra, ò hazienda, y hágase la diligencia posible para que se satisfaga, ó declare” (Noydens, 1671: 233-234).

Por lo que respecta al testamento, en éste el descargo de lo temporal iba ligado a lo espiritual, según se refleja en la disposición de las clausulas testamentarias. Así, el cristiano que otorgaba testamento no sólo debía ordenar los asuntos temporales, que entre otros pasaba por el reparto de bienes, sino indicar las condiciones de su enterramiento, el número de misas y oraciones que se debían decir por su alma, según la cuantía de sus bienes, con el fin de reparar en lo posible el mal uso que hubiese hecho de éstos durante su vida (Bejarano Rubio, 1988: 19). Por tanto, primeramente, con el testamento el cristiano pretendía cumplir con sus acreedores y con la justicia,

DE COMPUTIS Revista Española de Historia de la Contabilidad Spanish Journal of Accounting History 
restituyendo los agravios personales a los que quedasen en vida; luego procuraba justificar el uso de esos bienes que de acuerdo al camino de virtud señalado por Dios debía hacer. Estas pretensiones quedaban recogidas en expresiones como: "para descargo de mi conciencia otorgo y ordeno mi testamento en la manera siguiente”.

En las fórmulas testamentarias, el uso de los conceptos de cargo y descargo queda presente al justificar el testador las donaciones: "para descargo de cualquier culpa o cargo que agraviara la conciencia”. Y es que los testadores pretendían así decir las verdades del barquero, ansiando subsanar las ocultaciones y fraudes realizados en su vida a las puertas de la muerte, pretendiendo así descargar su ánima. En definitiva, las últimas voluntades permitían ajustar en buena conciencia aquellas obras que quedaban pendientes de resolver en esta vida para que la cuenta saliera justa a la espera de ser juzgado.

Recientemente, aproximándose a estos aspectos, Juan Triviño (2012) en su tesis doctoral señala como clarificadora de esta postura del testador de creer plenamente en justicia y verdad antes de que le llegase la hora de la muerte. Sin embargo, cuando el testador consideraba que el daño era irremediable, recurría a las misas y obras pías por el descargo de la propia conciencia (Martínez Gil, 2000: 548). También con las misas el testador pretendía no sólo descargarse de sus propios encargos, sino los de familiares.

Además en el momento de testar, convenía incluso pedir perdón por supuestos daños que se hubieran podido causar inadvertidamente por error u omisión. De esta manera el testador deja estipulada la petición por sí y por sus difuntos y por sus acreedores a nivel de caridad o por olvido: “Al faltar la memoria concreta de cada caso, se deja ese ajuste último en el ofrecimiento de misas, de tal modo que moralmente quedase purificada su propia conciencia” (Triviño, 2012: 184). Deducimos pues que en previsión de un alcance en contra se pretende hacer pagar éste con misas para que la cuenta quedase finalmente saldada.

\section{2.- El juicio particular ante Dios por cargo y descargo}

Después de la muerte llegará el juicio particular ante Dios. El concepto de juicio se debe considerar desde diferentes perspectivas: jurídicas, éticas y religiosas, en relación con la dimensión de la vida humana en sus relaciones con Dios. También, desde la perspectiva religiosa, existe un juicio universal, además del juicio particular del cristiano ante Dios. Este último, al que nos referimos, se plantea como la cuenta que debe dar el factor, administrador o gestor que recibe unos bienes de cuyo uso se ve obligado a responder, reforzando el significado jurídico de los conceptos de cargo y descargo o data.

En esta cuenta el cargo se compondría del agregado y cumulo de beneficios, bienes, gracias, favores, mercedes y otros dones concedidos y hechos para él y de los que está obligado a responder como fiel cristiano, reconociendo a su bienhechor. En descargo o data se tomaría el uso que el cristiano hace de esos dones en la tierra. Para

DE COMPUTIS Revista Española de Historia de la Contabilidad Spanish Journal of Accounting History 
saldar la cuenta, el descargo tendría que ir en función del cargo, siendo mayor la exigencia cuando el cargo es más, es decir, cuando era mayor lo recibido.

Las referencias a la rendición de cuentas a Dios no sólo las encontramos en los textos religiosos, teológicos o morales, también en Las Siete Partidas, cuerpo jurídico de contenido humanístico, se trata de la rendición de cuentas que el hombre debe dar a Dios (Partida I, Ley 30, Título 4) en los siguientes términos: “... á la muerte naturalmient, debe siempre estar aparejado como le dé buena cuenta de los fechos que fizo, et de cómo mejoró su vida faciéndolos buenos, et non desdeñar sin asconder los bienes que de Dios hobo, mas acrecentallos et ganar todavía su amor con ellos”.

El tema de la rendición de cuentas o juicio particular del cristiano ante Dios también se trata con frecuencia en los tratados de oración, meditación y devoción. En uno de Fray Luis de Granada (1559: 156) se dice:

"Imagina que estás ya presente a este juicio, y que toda la corte del cielo está aguardando el fin de esta sentencia, donde se hará el cargo y el descargo de todo lo recibido hasta el cabo de la agujeta. Allí se pedirá cuenta de la vida, de la hacienda, de la familia, de las inspiraciones de Dios, de los aparejos que tuvimos para bien vivir, y sobre todo de la sangre de Cristo, y del uso de sus Sacramentos; y allí será cada uno juzgado según la cuenta que diere de lo recibido”.

El cargo y descargo son dos elementos fundamentales en el juicio. Sin ambos el juicio quedaría invalidado, tal y como señala Fray Luis de León en los comentarios al Libro de Job. Job, hombre justo y perfecto, bendecido con riquezas es tentado por Satanás con el permiso de Jehová para probarlo. Las propiedades y los hijos de éste son destruidos y aun así Job sigue alabando a Jehová. Al justificar Fray Luis: "porque dijo Job: Justo fui, y Dios apartó mi juicio", el autor comenta que Dios no fue por eso injusto con Job o que se le había impuesto a éste falsamente algún delito: "sino decía que este su trabajo no era pena de culpa, ni se le daba Dios por ejecutar en él su debida justicia; y que ansí en este su caso no había cargo, ni descargo, ni condenación, ni ninguna otra cosa de las que son propias al tribunal y al juicio” (1527-1591: 227).

Sobre la composición del cargo y descargo que se hará en el juicio particular a cada cristiano existen diferentes referencias. Un racionero de la Catedral de Toledo, Pedro Sánchez, en su Árbol de consideración y varia doctrina (1584) dedica un capítulo a estas cuestiones titulado: "cuenta estrecha que a de dar el que recibe mucho" (BCLM, FA, 4-8661: 32r-32v), donde pone de manifiesto el mayor rigor que se le juzgará al que recibe mucho de Dios, pues "y de la mayoría y preeminencia desta dignidad, se puede inferir la mayor cuenta que ha de dar a Dios. El que mando y autoridad ha recibido de su mano, este ha de dar mas estrecha cuenta”. Por tanto, el cargo no era igual para todos, como tampoco lo eran los bienes y gracias recibidos, ni en consecuencia el juicio: "Cosa es muy digna de temer a los que emos recebido grandes dignidades del autor del mundo, no seamos juzgados con mayor rigor: porque tanto crece la obligación de la virtud, quanto crecen las razones de los bienes que recebimos”. De esta forma, cuanto mayor

DE COMPUTIS Revista Española de Historia de la Contabilidad Spanish Journal of Accounting History 
era el cargo, mayor debía ser el descargo, es decir, la responsabilidad exigida sobre lo dado. Ésta no era sólo la de custodia sino la de su acrecentamiento para el bien.

Además, al cúmulo de dones temporales (hacienda, familia y aparejos para bien vivir) habría que añadir al cargo de la cuenta que debía dar el cristiano otro componente, que sería el uso que éste da de las revelaciones divinas y de los sacramentos:

"Mire ahora cuan espantable será el pecador, cuando le hagan cargo, no solo de todo lo que es, y de toda su vida, sino de o que es Dios, de la encarnacion, pasión, vida y muerte de Cristo, que tantas veces se le ha dado en el sacramento de su cuerpo y sangre. El homicida, que es en cargo la vida de un hombre, aunque fuese de un malhechor, teme si le prenden y sacan á juicio. Pues el que es en cargo la vida de Dios, ¿cómo no tiembla? ¡O qué tremenda cosa cuando entre una vil criatura en juicio con su criador, y le pidan cuenta de la Sangre de Cristo, cuyo precio es infinito! ¿Qué descargo podrá dar á este beneficio, y á los demás de que le han de pedir cuenta rigurosa, desde el mayor hasta el menor? (Nieremberg, 1847, v.3: 459).

A esto mismo se refieren otros autores como María de Jesús cuando trata del “Cargo de los que no frequentan la Sagrada Comunion”. Ésta se pregunta: “Qué descargo darán los hombres en el juicio, de aver tenido consigo al mismo Dios Sacramentado en la Iglesia, esperando que vayan à recibirle para llenarlos de la plenitud de sus dones, y han despreciado este mefable amor,...” (María de Jesús, 1696: 406).

En el mismo sentido, Pedro Rodríguez de Monforte en su obra Sueños mysterioros de la Escritura, en discursos sagrados, políticos y morales (1687: 191) dice sobre el mayor de los cargos que se ha de hacer a un cristiano el día del juicio: "El cargo que nos haze Dios, es por los libros de su Ley, que estando cerrada la gloria por la culpa, él la abrió con su muerte, el descargo es las virtudes, para que en fé de ellas se les dé à los Santos como Corona el Cielo.”

Ante la dificultad de descargarse de este último cargo, otros autores se lamentan: "O qué tremenda cosa, quando entre una vil criatura en juicio con su Criador, y le pidan cuenta de la Sangre de Christo cuyo precio es infinito! Qué descargo podrá dar á este beneficio, y á los demás de que le han de pedir cuenta rigurosa, desde el mayor hasta el menor? (Nieremberg, 1777: 134-135).

Con este planteamiento y según la doctrina cristiana, en el juicio se dictará una sentencia justa y verdadera, en base al verdadero conocimiento de las cosas, de lo que resultará también un alcance justo. A este respecto, el racionero Pedro Sánchez (1584, BCLM, FA, 4-8661: 32r-32v) aborda la sentencia en los siguientes términos:

“...y el que no ha aprovechado con el talento, que ha recebido: siendo tan grande como es el del rey dado, señorio, o imperio temporal, o espiritual y ecclesiastico, bien tiene porque temer aquella sentencia que se pronuncio contra aquel que no aprovecho, ni mejoro el talento que le fue encomendado. Echad a este

DE COMPUTIS Revista Española de Historia de la Contabilidad Spanish Journal of Accounting History 
desaprovechado, e inútil siervo en las tinieblas exteriores: donde aura lloro, y rechinar de dientes”.

El mismo autor insiste nuevamente en el cargo y descargo como procedimiento para rendir cuentas:

"Y como en estos imperios, reynados, y dignidades del mundo, aya tantos estropieços, y peligros, no sabe el hombre como caminara por ellos, ni si tendrá la abilidad, y suficiencia que requieren, y por consiguiente no se puede saber que tal será la cuenta que se ha de dar a Dios destos estados tan preeminentes, y como saldrá el cargo y descargo".

Finalmente, tomando estas últimas consideraciones sobre la rendición de cuentas, la contabilidad se elevaría a la categoría de ciencia moral, tal y como la calificó Pio XII en 1953 en su discurso a los asistentes a un Congreso Internacional de Expertos Contables en Florencia. Estas declaraciones fueron recogidas por el profesor Della Penna en un artículo publicado hace ya más de cincuenta años en la revista Técnica Contable (Della Penna, 1956: 361). Según este autor, el Pontífice justificaba entonces esta valoración por la alta función de control que la contabilidad tenía en la economía familiar, en las empresas y en el Estado.

\section{Conclusiones}

El procedimiento de cargo y descargo o data en general estaba relacionado, por una parte, con la responsabilidad que recibe un sujeto al que se le encomienda un oficio y encargo del mismo (cargo); y, por otro lado, con la satisfacción, respuesta o excusa del cargo hecho (descargo). Por extensión, la clave sobre la forma de tomar la cuenta y razón por cargo y data está en general en dar respuesta de la carga u obligación aneja a un estado, empleo u oficio y en eso estaba la mayor responsabilidad y, por tanto, la obligación de rendir cuentas por este procedimiento.

Ahora bien, en esta formulación de la cuenta y razón por cargo y data se adivina un proceder fundamentado en tres planos: contable, jurídico y moral. El primero está ligado a la cuantificación y registro de ambos conceptos, cargo y data, y por diferencia el alcance o saldo de la cuenta. El segundo considera el contenido de la cuenta como cosa juzgada, con la obligación legal que tiene el dador de la cuenta de entregar o restituir lo mal llevado, cuya sustancia se enmarca en el derecho de obligaciones. Finalmente, el tercer plano tiene que ver con la necesidad del individuo de subsanar las ocultaciones y fraudes realizados durante su vida, descargando su conciencia o su ánima.

En definitiva, la contabilidad, el derecho y la moral se conjugan a la perfección en la forma de dar un sujeto la cuenta y razón por cargo y data, ligada tradicionalmente a la asunción de responsabilidades. En este caso se manifiesta contablemente la deuda u obligación de reparar o satisfacer el alcance, que pone de manifiesto la buena o mala gestión de las rentas de un tercero (responsabilidad económica), la capacidad para reconocer y aceptar las consecuencias de un encargo (responsabilidad jurídica o legal) y

DE COMPUTIS Revista Española de Historia de la Contabilidad Spanish Journal of Accounting History 

morales del método de cargo y descargo o data por el que se rendían cuentas

la obligación que resulta del compromiso contraído para alguien al que se le han dictado unas normas de comportamiento (responsabilidad moral y en juicio de conciencia).

\section{Bibliografía}

Abella, J. (1885): De los contratos administrativos con el Estado, la Provincia y el Municipio, Madrid.

Aced y Bartrina, F. (1941): Curso de contabilidades oficiales: estado, provincia, municipio, Reus. Imprenta de D. José G. de la Peña, Madrid.

Bejarano Rubio, A. (1988): El hombre y la muerte. Los testamentos murcianos bajomedievales, Ayuntamiento de Cartagena.

Calvo, M. (2005): "Rendición de cuentas de los administradores del obispado en sede vacante en España, siglos XVIII-XIX”, Revista de Contabilidad, 8 (15): 169-182.

Calvo, M. y Castro, C. (2005): "El mayordomo y la contabilidad parroquial. Control y rendición de cuentas. Villa de Agüimes 1730-1830”, De Computis: Revista Española de Historia de la Contabilidad, 3: 4-32.

Capelo Bernal, M.D. (2007), "La contabilidad del almacén de Agüera entre los siglos XVIII y XIX. Un estudio sobre su evolución desde el registro por cargo y data hasta la partida doble”, Revista Española de Financiación y Contabilidad, 36 (135): 453-479.

Carmona Pidal, J. (2001): Aristocracia terrateniente y cambio agrario en la España del siglo XIX. La Casa de Alcañices (1710-1910). Ávila: Junta de Castilla y León.

Carmona, S., Céspedes, J. y Gómez, D. (1997): "Inercia contable: una aproximación histórica a las Salinas de Roquetas (1800-1869)”, Revista Española de Financiación y Contabilidad, 26 (91): 427-475.

Casares López, M. (2009): "La ciudad palatina de la Alhambra y las obras realizadas en el siglo XVI a la luz de sus libros de cuentas”, De Computis: Revista Española de Historia de la Contabilidad, 10: 3-130.

Castillo, D. del (1542): Tratado de Cuenta hecho por el licenciado Diego del Castillo natural de la ciudad de Molina, $2^{\mathrm{a}}$ ed. Salamanca: Imprenta de Juan de Junta.

Caunedo del Potro, B. (2003): "Algunas consideraciones sobre los libros de cuentas. El tratado del licenciado Diego del Castillo”, Historia, Instituciones y Documentos, 30: 145-157.

Cillanueva de Santos, M.A. (2008): "La contabilidad de los Libros de Fábrica de la Catedral de Segovia durante su edificación: 1524-1685”, De Computis: Revista Española de Historia de la Contabilidad, 9: 3-47.

--------- (2010): “Cobros y pagos para la edificación de una catedral: Segovia 1524-1699”, De Computis: Revista Española de Historia de la Contabilidad, 10: 157-182.

Covarrubias, S. de (1611): Tesoro de la Lengua Castellana o Española. Madrid: Castalia, 1995.

Damián López-Manjón, J. (2009): "Contabilidad y crisis de las casas nobiliarias españolas en el siglo XIX”, De Computis: Revista Española de Historia de la Contabilidad, 11: 30-52.

Damián López-Manjón, J. y Gutiérrez Hidalgo, F. (2006): “Asignación de gastos e ingresos como mecanismo de arbitraje: El caso del Colegio-Universidad de Osuna (1796-1800)”, De Computis: Revista Española de Historia de la Contabilidad, 5: 147-165.

Della Penna, F. (1956): “La Contabilidad en la Biblia”, Técnica contable, p. 361.

Donoso Anes, A. (2008): "Organización y funcionamiento administrativo y contable de la Real Hacienda de Indias en tiempo de los Austrias a la luz de la legislación aplicable”, De Computis: Revista Española de Historia de la Contabilidad, 9: 48-96.

Donoso Anes, R. (1996): Análisis de las prácticas contables desarrolladas por la tesorería de la Casa de la Contratación de las Indias de Sevilla (1503-1717), Universidad de Sevilla.

Exercicio quotidiano, con diferentes oraciones para asistir con devoción al Santo Sacrificio de la misa, y otras para antes y después de la confesión, y Sagrada Comunion (1795), Imprenta de la Viuda de Ibarra, Madrid.

Febrero, J. (1797): Librería de escribanos é instrucción jurídica theorico, práctica de principiantes, 3 tomos, $4^{\mathrm{a}}$ impresión, Madrid: Imprenta de la viuda e hijo de Marín.

DE COMPUTIS Revista Española de Historia de la Contabilidad Spanish Journal of Accounting History 
Gallego, E., Rivero, D. y Ramos, A. (2007): “Los flujos de efectivo en una economía monástica. Estudio del Arca de la Comunidad del Monasterio de Santa María la Real de Oseira (1614-1698)”, De Computis: Revista Española de Historia de la Contabilidad, 6: 3-31.

García Ruipérez, M. (2005): “Los contadores municipales en la Corona de Castilla (siglos XIV-XVIII)”, De Computis: Revista Española de Historia de la Contabilidad, 5: 53-99.

González Ferrando, J.Ma . (1988): "De las tres formas de llevar cuenta y razón según el licenciado Diego del Castillo, natural de Molina”, Revista Española de Financiación y Contabilidad, 17 (55): 187222.

(1991): "Bartolomé Salvador de Solórzano, adelantado de la contabilidad aplicada en España”, Revista Española de Financiación y Contabilidad, 21 (68): 713-755.

(1994): "Una ayuda indirecta a la introducción de la partida doble en la Real Hacienda de Indias: La Real Cédula de 18 de agosto de 1596 sobre libros de cuentas”, Revista Española de Financiación y Contabilidad, v. 24 (80): 647-674.

Granada, L. (1559): Libro de la oración y meditación, Obras Completas, T.1, Fundación Universitaria Española, 1994.

Hernández Borreguero, J.J. (2008): "El Hospital de Santa Marta de Sevilla: gestión económica y contable (siglo XV a XVIII)”, XIII Encuentro ASEPUC, Albacete.

Hernández Esteve, E. (1985): "Pedro Luis de Torregrosa, primer contador del libro de Caxa de Felipe II. Introducción de la contabilidad por partida doble en la Real Hacienda de Castilla (1592)”, Revista de Historia Económica, año III, n.2, pp.221-245.

(1986): Establecimiento de la partida doble en las cuentas centrales de la Real Hacienda de Castilla (1592), Banco de España, 1986.

(2007): "La Contabilidad por cargo y data y sus textos en el panorama contable español de los siglos XVI y XVII”, Homenaje al Prof. Dr. D. Luis Pérez Pardo, Escola Universitaria d`Estudis Empresarials de Barcelona: 161-224.

Jesús, María De (1696): Mystica Ciudad de Dios milagro de su omnipotencia, y abismo de la gracia, Historia divina y vida de la Virgen Madre de Dios II, Amberes.

Jócano y Madaria, S. (1793): Disertación crítica y apologética del arte de llevar cuenta y razón. Madrid: Oficina de D. Gerónimo Ortega y Herederos de Ibarra.

Jouanique, P. (1987): "La regla quien recibe, debe: una herencia de antigua raigambre en la contabilidad moderna”, Técnica Contable, 461: 247-258. Tr. E. Hernández Esteve.

León, Fray Luis (1527-1591): Textos completos. El Libro de Job, Colección Tecnibook, Buenos Aires, 2011.

Lillo Criado, J.L. y Álvarez López, J.Ma . (2006): “Contabilidad y cobros de rentas en la Santa Capilla de San Andrés de Jaén”, De Computis: Revista Española de Historia de la Contabilidad, 4: 68118.

López Pérez, Ma .M. y Pérez Morote, R. (2007): "El sistema de información contable del Hospital de San Julián de Albacete entre 1838 y 1859”, De Computis: Revista Española de Historia de la Contabilidad, 6: 55-117.

Martínez Alcubilla, M. (1848): Juzgado de Alcaldes ó Tratado General Teórico-Práctico de los deberes y atribuciones judiciales de los alcaldes, sus tenientes y regidores, Burgos.

Martínez Gil, F. (2000): Muerte y sociedad en la España de los Austrias, Universidad de Castilla-La Mancha, Cuenca.

Maté, L., Prieto, B. y Tua, J. (2008): “Contabilidad, información y control en un contexto de actividades económicas diversificadas en la Edad Moderna: El Monasterio de Silos y su sofisticado sistema contable”, De Computis: Revista Española de Historia de la Contabilidad, 9: 136-229.

Mirón, P., Escobar, B. y Hernández, J.J. (2011): “Las cuentas públicas de Ultramar en la segunda mitad del siglo XIX: normativa y procedimiento de fiscalización referidos al caso de Puerto Rico (año 1880-81)”, De Computis: Revista Española de Historia de la Contabilidad, 14: 121-155.

Nieremberg, J.E. (1777): Diferencia entre lo temporal y eterno y crisol de desengaños con la memoria, Barcelona. (1847): Escritores místicos españoles, T. 3, Baudry, París.

Noydens, Padre Benito Remigio (1671): Promputuario de questiones practicas y casos repentinos en la Teología moral, para examen de curas y confessores, Barcelona.

Novísima Recopilación de las Leyes de España (1805-1807). Facsímil: B.O.E., Madrid, 1976 (6 tomos).

DE COMPUTIS Revista Española de Historia de la Contabilidad Spanish Journal of Accounting History

No. 19

Diciembre 2013 
Pérez, A. (1624): Relaciones de Antonio Perez, secretario de Estado, que fue del Rey de España don Phelippe II deste nombre. Según la copia impresa en París.

RAE (1729): Diccionario de la lengua castellana que explica el verdadero sentido de las voces, su naturaleza y calidad, con las phrases o modos de hablar, los proverbios o refranes, y otras cosas convenientes al uso de la lengua, Tomo II, Madrid.

Ripia, J. de la, (1796): Práctica de la administración y cobranza de las rentas reales, y visita de los ministros que se ocupan en ellas. Corregida por el Licenciado don Diego María Gallard. Madrid: Oficina de don Antonio Ulloa,.

Rodríguez Berriz, M. de (1887): Diccionario de la Administración de Filipinas, $1^{\text {a }}$ ed., T. 7, Manila.

Rodríguez De Monforte, P. (1687): Sueños misteriosos de la escritvra, en discvrsos sagrados, políticos y morales con un elenco de sermones para las dominicas de adviento, Madrid: Imprenta de Antonio Román.

Rodríguez, A., Morala, B., Gutiérrez, C. y Fernández, Y. (2010): “La contabilidad en los libros de la Catedral de León durante la restauración del siglo XIX: cobros y pagos de la última etapa (18801901)”, VII Encuentro de Trabajo de Historia de la Contabilidad de AECA, León.

Rubín Córdoba, F. y Mallado Rodríguez, J.A. (2003): "El inicio del método de la partida doble en el Ayuntamiento de Sevilla. Año 1570”, Revista Española de Financiación y Contabilidad, 117: 349-394.

(2010): "La contabilidad en el cabildo y regimiento de Sevilla. Del formalismo en el auge de la monarquía hispánica al presupuesto y control de la Ilustración”, VII Encuentro de Trabajo de Historia de la Contabilidad de AECA, León.

Sala, J. (1856): Digesto Romano-Español. Madrid: Imprenta de la viuda de Domínguez. Tr. Pedro López Claros y Francisco Fábregas del Pilar.

Salvador De Solórzano, B. (1590): Libro de Caxa y Manual de Cuentas de mercaderes, y otras personas, con la declaración dellos. Madrid: AECA, 1990.

Salvador Montiel, Ma.D. y Ruiz Lamas, F.C. (2011): "El régimen administrativo y contable del Hospital de Caridad de La Coruña en el siglo XVIII”, De Computis: Revista Española de Historia de la Contabilidad, 14: 156-178.

Sánchez, P. (1584): Árbol de consideración y varia doctrina (1584), dedica un capítulo a estas cuestiones, titulado: "cuenta estrecha que a de dar el que recibe mucho" (Biblioteca de Castilla-La Mancha, Fondo Antiguo, 4-8661: 32r-32v)

Las Siete partidas del rey don Alfonso El Sabio, cotejadas con varios códices antiguos por la Real Academia de la Historia (1807). Madrid: Imprenta Real.

Triviño, J. (2012): Historia y teología del retablo mayor de Sonseca (1574-2000), Universidad Eclesiástica San Dámaso, tesis doctoral inédita, Madrid.

Vlaemminck, J.H. (1961): Historia y doctrinas de la contabilidad. Versión española, revisada y ampliada por J.M . González Ferrando, Madrid: EJES.

Zamora, Fray Juan de (1799): "Sobre los usos en que los Eclesiásticos deben invertir el sobrante de su renta”, Eclesiástico perfecto, tercera impresión, Madrid.

Susana Villaluenga De Gracia es Profesora Titular de Economía Financiera y Contabilidad en la Facultad de Ciencias Jurídicas y Sociales (Universidad de Castilla-La Mancha). Su e-mail es: Susana.Villaluenga@uclm.es

Susana Villaluenga De Gracia is Associate professor of Accounting and Finance at the Universidad de Castilla-La Mancha, Toledo, Spain. Her e-mail is: Susana.Villaluenga@uclm.es

DE COMPUTIS Revista Española de Historia de la Contabilidad Spanish Journal of Accounting History 